\title{
Assessing the Toxicological Interaction Effects of Imidacloprid, Thiamethoxam, and Chlorpyrifos on Bombus Terrestris Based on the Combination Index
}

\section{Yongkui Zhang}

Chinese Academy of Agricultural Sciences

\section{Dongqiang Zeng}

Guangxi University

Lu Li

Chinese Academy of Agricultural Sciences

\section{Xiuchun Hong}

Chinese Academy of Agricultural Sciences

Hongmei Li-Byarlay

Central State University

Shudong Luo ( $\square$ luoshudong@caas.cn )

Chinese Academy of Agricultural Sciences

\section{Research Article}

Keywords: chlorpyrifos, imidacloprid, thiamethoxam, oral acute toxicity

Posted Date: December 1st, 2021

DOI: https://doi.org/10.21203/rs.3.rs-1074328/v1

License: (c) (i) This work is licensed under a Creative Commons Attribution 4.0 International License. Read Full License

Version of Record: A version of this preprint was published at Scientific Reports on April 15th, 2022. See the published version at https://doi.org/10.1038/s41598-022-09808-3. 


\section{Abstract}

In modern agricultural production, a variety of pesticides are widely used to protect crops against pests. However, extensive residues of these pesticides in the soil, water, and pollen have negatively affected the health of nontarget organisms, especially among pollinators such as bumblebees. As an important pollinator, the bumblebee plays a vital role in agricultural production and the maintenance of ecosystem diversity. Previous research has focused on the effects of a single pesticide on pollinating insects; however, the synergistic effects of multiple agents on bumblebees have been not studied in detail. In our test, the individual and combined toxicities of chlorpyrifos, thiamethoxam, and imidacloprid to bumblebees after $48 \mathrm{~h}$ of oral administration were documented by the equivalent linear equation method. Our results showed that the toxicity of each single pesticide exposure, from high to low, was imidacloprid, thiamethoxam, and chlorpyrifos. All binary and ternary combinations showed synergistic or additive effects. Therefore, our research not only shows that the mixed toxicity of insecticides has a significant effect on bumblebees, but also provides scientific guidelines for assessing the safety risks to bumblebees of these three insecticide compounds. In assessing the risk to pollinating insects, the toxicity levels of laboratory experiments are much lower than the actual toxicity in the field.

\section{Introduction}

Pollinators play key roles in the sustainable development of ecosystems and in agricultural production ${ }^{1,2}$. Previous studies have suggested that pollination services depend not only on managed bees, such as honeybees ${ }^{3}$, but also on wild bees, such as bumblebees, leafcutter bees, and mason bees ${ }^{4}$. It has been reported that pollinators contribute $9.5 \%$ of the total value of human food production worldwide ${ }^{5,6}$. The bumblebee (Bombus sp.) is an indispensable wild pollinator in native plant communities throughout the temperate ecosystem ${ }^{7}$. Especially in recent years, with the development of artificial domestication and facility agriculture, bumblebees have been widely used as pollinators in greenhouses because of their large size, hair covering, weak phototaxis, tolerance to low temperatures, and their buzz for acoustic shock pollination ${ }^{8-10}$. Velthuis and van Doorn reported that more than 10,000 bumblebee colonies in Europe are utilized for crop pollination per year and that the annual output value is more than 12 billion euros ${ }^{11}$. The pollination service of honeybees (bees) is estimated to be worth more than 15 billion U.S. dollars to American agriculture every year ${ }^{12}$.

However, the abundance and diversity of wild pollinators such as bumblebees and managed honeybees have been in continuous decline in some countries and regions ${ }^{3,13}$. Many factors are believed to be responsible for this reduction, such as the large-scale use of chemical pesticides and their metabolites ${ }^{14}$, parasitic infestation ${ }^{2,15}$, pathogenic bacterial infection ${ }^{16,17}$, habitat loss ${ }^{18}$, a lack of nutrition ${ }^{19}$, and climate change ${ }^{20}$. Among them, pesticides and their metabolites were considered the main reason for this reduction ${ }^{14,21}$. Research evidence has shown that the survival rate of worker bumblebees decreases after exposure to $10 \mathrm{ppb}$ of imidacloprid, especially in early spring, when the bumblebees feed on food contaminated with imidacloprid and thiamethoxam, which significantly reduces their reproductive ability $22-24$. In addition, Ellis et al. ${ }^{25}$ found that pesticide-exposed bumblebees were more likely to die prematurely and that the surviving bees had a $46 \%$ lower final weight than control bees.

In fact, a variety of pesticide residues in the pollen and nectar may threaten the survival of pollinators. Mullin et al. ${ }^{26}$ discovered more than 121 different pesticides and metabolites in similar samples in North America. Different types of fungicides, herbicides, and insecticides, such as pyrethroid and neonicotinoid insecticides, have been found in pollen and beebread samples in the United States, France, the United Kingdom, Spain, Greece, and China ${ }^{3,27-33}$. Tong et al. ${ }^{33}$ detected a variety of pesticide residues in 189 pollen and 226 bee pollen samples collected in China. The pesticide with the greatest content was imidacloprid (with an average content in pollen samples of $41.9 \mathrm{ng} / \mathrm{g}$ and in beebread samples of $19.3 \mathrm{ng} / \mathrm{g}$ ), thiamethoxam (with an average content in pollen samples of $44.9 \mathrm{ng} / \mathrm{g}$ and in beebread samples of $12.8 \mathrm{ng} / \mathrm{g}$ ), and chlorpyrifos (with an average content in pollen samples of $49.4 \mathrm{ng} / \mathrm{g}$ and in beebread samples of $41.4 \mathrm{ng} / \mathrm{g}$ ). Similarly, Wen et $a^{\beta 4}$. also found that imidacloprid and chlorpyrifos residue in the oilseed rape pollen and nectar samples. 
Obviously, bumblebees may be negatively affected by more than one insecticide simultaneously. However, previous studies have mainly been focused on the effects of a single insecticide on bumblebees rather than the synergistic effects of several insecticides combined. Here, we tested the acute oral toxicity of three insecticides-two neonicotinoids, imidacloprid and thiamethoxam, and one organic phosphorus, chlorpyrifos-based on either individual or joint exposures as close to field conditions as possible.

\section{Materials And Methods}

Bumblebees. Experiments were conducted between April and May 2019. Twenty-five commercial colonies of B. terrestris were purchased from Koppert Agricultural Co., Ltd. (Beijing, China). Each colony contained about 200 workers, a brood at all developmental stages, and a laying queen. The bumblebees were reared on a diet that included pollen and nectar and were provided by the company in an incubator with continuous darkness, at a temperature of $25 \pm 1{ }^{\circ} \mathrm{C}$ and a relative humidity of $60 \pm 10 \%$.

Insecticides. Chlorpyrifos (CAS No. 2921-88-2, 96\% Technical material) was supplied by the Hunan Research Institute of Chemical Industry (Hunan, China). Imidacloprid (CAS No. 138261-41-3, 96\% TC) was supplied by Shandong Zhongnong United Biological Technology Co., Ltd. (Shandong, China). Thiamethoxam (CAS No. 153719-23-4, 97\% TC) was obtained from the Hailier Pesticides and Chemicals Group (Shandong, China). Each insecticide was dissolved in dimethyl sulfoxide and diluted in a $50 \%(\mathrm{w} / \mathrm{w})$ sugar solution as described by Yue et al. ${ }^{34}$. Each stock solution was diluted to six test concentrations by using a calibrated micropipette and volumetric flasks.

Toxicity assessment. The acute oral toxicity of the insecticides to the worker was tested according to the method recommended by the $\mathrm{OECD}^{35}$ (Organization for Economic Co-operation and Development). Briefly, one leg of the same size workers was clamped gently with a forceps, and the bees were quickly transferred to a thermostat-controlled wooden box (dimensions $12 \mathrm{~cm}{ }^{\prime} 8 \mathrm{~cm}{ }^{\prime} 8 \mathrm{~cm}$; Fig. 1). Fifteen workers were placed in each wooden box in the dark at room temperature $\left(25 \pm 1^{\circ} \mathrm{C}\right)$ and a relative humidity of $60 \pm 10 \%$ with a sufficient amount of noncontaminated $50 \%$ sugar solution (w/w). The bees were left alone for at least 8 hours for adaptation. The experiment was conducted when the mortality rate of bumblebees in the wooden box did not exceed $10 \%$. Then $300 \mu \mathrm{L}$ of the $50 \%$ sugar solution was either contaminated with a insecticide or fed uncontaminated to the worker bumblebees via a $5 \mathrm{~mL}$ syringe with the tip removed (Fig. 2) for 6 hours, followed by 2 hours of starvation. The sugar solution was immediately replaced with a sufficient amount of uncontaminated sugar solution once the $300 \mu \mathrm{L}$ sugar solution had been consumed over the 6 hours. The mass of each test solution was weighed and recorded before and after each feeding. Six groups of workers (a total of 90 bees) from the same colony were treated with a sugar solution containing six different concentrations of insecticides. Triplicate experiments were performed with 270 worker bees for each treatment. In total, seven treatments were performed: (1) chlorpyrifos, (2) imidacloprid, (3) thiamethoxam, (4) chlorpyrifos + imidacloprid, (5) chlorpyrifos + thiamethoxam, (6) imidacloprid + thiamethoxam, (7) chlorpyrifos + imidacloprid + thiamethoxam. The total number of bees used for the experiment was 1,890.

All binary and ternary insecticide toxicities were administered as described by Liu et al. ${ }^{36}$. Stock solutions of chlorpyrifos, imidacloprid, and thiamethoxam were prepared as described above and used in three binary combinations (chlorpyrifos + imidacloprid; imidacloprid + thiamethoxam; chlorpyrifos + thiamethoxam) and a ternary combination (chlorpyrifos + imidacloprid + thiamethoxam). The constant combination ratios

were chlorpyrifos:imidacloprid, 0568:0.310; imidacloprid:thiamethoxam, 0.31:0.438; chlorpyrifos:thiamethoxam, 0.568:0.438; and chlorpyrifos:imidacloprid:thiamethoxam, 0.568:0.310:0.438 based on the individual median lethal dose $\left(\operatorname{LD}_{50}\right)$ toxicity such that the effects of the individual insecticides within the combination would be approximately equal. In addition, the mixed insecticides were diluted to six concentrations. All six concentrations were tested simultaneously to minimize experimental variations. 
Data analysis. A preliminary experiment suggested that evaporation of the sugar solution in the syringe did not significantly affect the mass change (a loss of about $0.001 \mathrm{~g}$ ). Therefore, the consumption of the sugar solution could be inferred from the differences before and after insecticide exposure. The mixtures were then converted from concentrations into doses in micrograms of the active ingredient per worker. The $\mathrm{LD}_{50}$ values were calculated by probit analysis using POLOPC software ${ }^{37}$.

The individual and combined toxic effects of insecticides on bumblebees were assessed using the median-effect equation described by Liu et al. ${ }^{36}$ and Chou and Talalay ${ }^{37}$ :

$f_{a} / f_{u}=\left(D / D_{m}\right)^{m}$

where $D$ is the dose of an insecticide, $D_{m}$ is the dose for a $50 \%$ effect, $f_{a}$ is the mortality influenced by $D$ (percentage of mortality), $f_{u}$ is the survival rate uninfluenced by $D$ (percentage of survival, $f_{u}=1-f_{a}$ ), and $m$ is the coefficient determining the shape of the dose-effect relationship.

By rearranging equation (1), we can obtain the following equations:

$f_{a}=1 /\left[1+\left(D_{m} / D\right)^{m}\right]$

$D=D_{m}\left[f_{a} /\left(1-f_{a}\right)\right]^{1 / m}$

Therefore, if we know the values for $m$ and $D_{m}$, we can easily assess the effect $\left(f_{a}\right)$ for any given dose $(D)$ in equation (2). In the same way, the dose $(D)$ can easily be calculated by the effect $\left(f_{a}\right)$ given in equation (3). In addition, if we take the logarithm of both sides of equation (1) and assume that $x=\log (D)$ and $y=\log \left(f_{a} / f_{u}\right)$, we can obtain the following middleeffect diagram:

$\log \left(f_{a} / f_{u}\right)=m \log (D)-m \log \left(D_{m}\right)$

In the median-effect plot in equation (4), we can easily determine the $D_{m}$, where $m$ for the $D_{m}$ means the antilog of the $x$ intercept and $m$ is the slope. Here, $m>1, m=1$, and $m<1$ signify sigmoidal, hyperbolic, and flat sigmoidal dose-effect curves, respectively. In addition, the linear correlation coefficient $(r)$ of the median-effect plot can reveal how the data conform to the median-effect plot, where $r=1$ shows excellent conformity.

Therefore, we can easily calculate the combination index $(\mathrm{Cl})$ values by using the $\mathrm{Cl}$ equation for a combination of $n$ insecticides, which is given as

$$
{ }^{n}(\mathrm{CI})_{x}=\sum_{j=1}^{n} \frac{(D) j}{\left(D_{x}\right) j}=\sum_{j=1}^{n} \frac{\left(D_{x}\right)_{1-n}\left[[D] j / \sum_{l}^{n}[D]\right\}}{\left(D_{m}\right)_{j} f\left(f_{a x}\right) j /\left[1-\left(f_{a x}\right) j\right]^{1 / m j}}
$$

where $(\mathrm{Cl})_{x}$ is the combination index for $n$ insecticides at $x \%$ effect $\left(f_{a}\right) ;\left(D_{x}\right)_{1-n}$ is the sum of the dose of $n$ insecticides causing $x \%$ effect $\left(f_{a}\right)$ in combination; [D]j/ is the proportionality of the dose of $n$ individual insecticides causing $x \%$ effect $\left(f_{a}\right)$ in combination; $\left.\left(D_{m}\right) j\left(f_{a x}\right) j /\left[1-\left(f_{a x}\right)\right]^{1 / m}\right\}$ is the dose of individual insecticides causing $x \%$ effect $\left(f_{a}\right)$; and $f_{a x}$ is the fractional effect $\left(f_{a}\right)$ at $x \%$ effect $\left(f_{a}\right)$, where $\mathrm{Cl}>1, \mathrm{Cl}<1$, and $\mathrm{Cl}=1$ indicate an antagonistic, synergistic, and an additive effect, respectively.

The computer program CompuSyn ${ }^{39}$ was used to calculate the parameters including the dose-response curve parameters, $\mathrm{Cl}$ values, $f_{a}-\mathrm{Cl}$ plot representing $\mathrm{Cl}$ versus $f_{a}$, the fraction influenced by a specific dose, and the polygonogram representation describing the antagonistic, additive, or synergistic effect of the insecticide combination.

\section{Results}


Toxicity of the three insecticides to bumblebees. All the controls had a mortality rate of $6.67 \%$ or less for acute toxicity, demonstrating the reliability of the tests. The results for each single insecticide indicated that imidacloprid had the highest toxicity ( $\mathrm{LD}_{50}$ of $0.310 \mu \mathrm{g} / \mathrm{bee}$; Table 1$)$ among the three individual insecticide treatments. The $\mathrm{LD}_{50}$ of thiamethoxam was $0.438 \mu \mathrm{g} /$ bee (Table 1), which was not significantly different from that of imidacloprid. The LD $_{50}$ of chlorpyrifos was 0.568 $\mu \mathrm{g} /$ bee (Table 1), which was significantly lower than that of imidacloprid. There was no significant difference in $L_{50}$ values between chlorpyrifos and thiamethoxam.

For the binary and ternary insecticide combinations, the two neonicotinoid insecticides (imidacloprid + thiamethoxam) were the most toxic $\left(\operatorname{LD}_{50}\right.$ of $0.205 \mu \mathrm{g} /$ bee; Table 1$)$. The $\mathrm{LD}_{50}$ value of the binary combination of chlorpyrifos and thiamethoxam was $0.224 \mu \mathrm{g} /$ bee (Table 1). The $L_{50}$ of the ternary combination of insecticides was $0.293 \mu \mathrm{g} / \mathrm{bee}$ (Table 1 ), indicating no significant difference among the combinations. Furthermore, the $\mathrm{LD}_{50}$ value for the binary combination of chlorpyrifos and imidacloprid $(0.860 \mu \mathrm{g} / \mathrm{bee})$ was significantly higher than those for the other binary and ternary insecticide combinations, indicating they had a lower toxicity.

The combined index. The parameters $D_{m}, m$, and $r$ for the three neonicotinoids individually and their total combinations and the mean $\mathrm{Cl}$ values of the total combinations are summarized in Table 2. For the individual insecticides, the $D_{m}$ values were $0.766,0.234$, and $0.436 \mu \mathrm{g} /$ bee for chlorpyrifos, imidacloprid, and thiamethoxam, respectively, and this result was consistent with the toxicity order of the three single insecticides after $48 \mathrm{~h}$ of exposure.

The antagonistic or synergistic effects were calculated based on equation (5) according to the $D_{m}$ and $m$ values for the single insecticides and their binary and ternary combinations ${ }^{40}$. The $\mathrm{Cl}$ values at $\mathrm{LD}_{10}, \mathrm{LD}_{50}$, and $\mathrm{LD}_{90}$ indicate the doses required to produce $10 \%, 50 \%$, and $90 \%$ bumblebee mortality, respectively (Table 2 ).

The results also indicated that the $\mathrm{Cl}$ values at $\mathrm{LD}_{10}(8.21)$ and $\mathrm{LD}_{50}(1.76)$ for the chlorpyrifos + imidacloprid combination were greater than 1 , showing a strong antagonistic effect. The same results were observed at $\operatorname{LD}_{10}(2.29)$ for the binary combination of imidacloprid + thiamethoxam and the ternary combination of chlorpyrifos + imidacloprid + thiamethoxam at $\mathrm{LD}_{10}$ (2.11). The other $\mathrm{Cl}$ values for the combinations at each point were less than 1 , indicating a strong synergy.

The $f_{a}-\mathrm{Cl}$ plot can also depict the relationship between a single insecticide and a mixture of insecticides (synergistic, antagonistic, or additive effect). The computer software CompuSyn uses a semiquantitative approach to simulate a graphic for any effect $\left(f_{a}\right)$. The polygonograms revealed interactions for all the binary and ternary combinations at the $0.1,0.5$, and 0.9 effect levels after $48 \mathrm{~h}$ of exposure (Fig. 3). The results suggested that only chlorpyrifos + thiamethoxam had a synergistic effect at the 0.1 effect level. At the 0.5 effect level, only the combination of chlorpyrifos + imidacloprid had an antagonistic effect. All the combinations showed synergistic effects at the 0.9 effect level. These results are consistent with the $\mathrm{Cl}$ values in Table 1. Except for imidacloprid, all the single neonicotinoids and their combinations fit the median-effect equation with an S-shaped dose-response curve (Fig. 4).

\section{Discussion}

Brief summary of the results. Our results showed solid measurements of $\mathrm{LD}_{50}$ not only in individual insecticides, but also in combinations of two or three insecticides, revealing the toxicity of the insecticide residues. Synergistic and additive effects from multiple insecticide residues were also detected, providing new evidence with which to study the toxicology of these residues in bumblebees.

Neonicotinoids were first introduced in the 1990s, and then became the most widely used class of insecticides in the world ${ }^{41}$. They can be found in the nectar, beebread, and honey of honeybees because of their water solubility and action as systemics ${ }^{42}$. Several studies have raised concerns that neonicotinoids may be having a negative effect on nontarget organisms, particularly on managed honeybees and other wild pollinators, such as bumblebees $23,43,44$. Among them, 
imidacloprid and thiamethoxam are found most commonly in the literature. Chlorpyrifos is one of the main organophosphates in use, and its residue has been reported in the nectar, beebread, and pollen of honeybees ${ }^{33}$.

The $\mathrm{Cl}$ provided the ability to predict the joint toxicity of multiple insecticides without characterizing the insecticides according to their chemical structure and mechanism of action, as has been done previously, for example, in an ecotoxicological evaluation of the effects of two insecticides and one herbicide on earthworms ${ }^{45}$, an examination of the toxicological interactions of lipid regulators in two aquatic bioluminescent organisms ${ }^{46}$, a study on the safety risks of three neonicotinoid mixtures to bees ${ }^{36}$, and an evaluation of the ecological risks of antibiotic mixtures to the aquatic environment ${ }^{47}$. Here, we investigated a series of interactions between two common neonicotinoids and an organophosphorus insecticide.

The results of our experiments indicated that as a single agent, imidacloprid is more toxic than chlorpyrifos or thiamethoxam. However, previous studies have shown that thiamethoxam is more toxic than imidacloprid to bees, which is exactly the opposite of our results. This disparity may be due to differences in the test insects and reagent types, given that ecotoxicity studies on different species with different nutritional levels may show completely different responses to the same toxic mixture ${ }^{46}$. We found that when multiple agents were mixed, as the effect gradually moved from 0 to 1 , the synergy between the insecticides became more and more obvious. This finding is similar to the results of Liu et al. ${ }^{38}$ but differs from those of Chen et al. ${ }^{45}$ and Wang et al. ${ }^{48}$. This difference may be related to calculation of the dosage of the insecticide used and our use of the equivalent linear equation method.

In addition, except for the chlorpyrifos + thiamethoxam combination, when the effect $\left(f_{a}\right)$ was close to 0 , it showed a high antagonism, and when the effect $\left(f_{a}\right)$ was close to 1 , it showed a synergistic effect. The full effect $\left(f_{a}\right)$ of the binary combination of chlorpyrifos + thiamethoxam was synergistic, whereas the binary combination of chlorpyrifos + imidacloprid and the ternary combination of chlorpyrifos + imidacloprid + thiamethoxam showed an antagonistic effect. The binary combination of chlorpyrifos + imidacloprid suggested a possible competitive relationship between the two. Chlorpyrifos and imidacloprid may be combined at the same site, or they may be combined in some way and act differently at different sites. Imidacloprid and thiamethoxam are agonists of nicotinic acetylcholine receptors and can selectively bind to nicotinic acetylcholine receptors ${ }^{49-51}$, but Soto-Mancera et al. ${ }^{52}$ reported that oxypyrifos oxon, a metabolite of chlorpyrifos, can specifically inhibit nicotinic acetylcholine receptors. Whereas the combination of chlorpyrifos and imidacloprid showed an antagonistic effect, the combination of chlorpyrifos and thiamethoxam showed a synergistic effect, which may be due to the difference between the main metabolites of the two.

One reason for the interaction between mixed insecticides is that these mother fluids can be rapidly metabolized into other chemicals in insects. Previous experiments ${ }^{53,54}$ have shown that imidacloprid and thiamethoxam can transform various metabolites in insects and that these metabolites have very different toxicity levels to the insects. Wiesner and Kavser ${ }^{54}$ reported that imidacloprid was about 10 and 16 times more active against the whitefly (Aleyrodidae) and green peach aphid (Myzus persicae) than the parent imidacloprid. The activity of imidacloprid nitrosimine was similar to that of imidacloprid. $\mathrm{N}$-demethylated thiamethoxam has an affinity for insect nicotinic acetylcholinerase receptors that is 1,000 times higher than that of thiamethoxam, and in insects, thiamethoxam is easily metabolized to clothianidin. Clothianidin itself belongs to the second generation of a neonicotinoid agent, which has a higher affinity for insect nicotinic acetylcholine receptors than does thiamethoxam ${ }^{53,54}$. Chlorpyrifos oxon, a metabolite of chlorpyrifos, can cause specific inhibition of nicotinic acetylcholine receptors.

Imidacloprid and thiamethoxam are representative of the neonicotinoid group of insecticides, which mainly block the normal conduction of the insect central nervous system by selectively controlling the nicotinic acetylcholinerase receptors in the insect nervous system, leading to paralysis and death of the insects ${ }^{55,56}$. Chlorpyrifos is a representative of the organophosphorus group, which destroys normal nerve activity by inhibiting the activity of acetylcholinesterase or cholinesterase $^{52}$. In fact, because of insect resistance to a single insecticide, people have already begun using insecticide 
compounding to achieve high efficiency and slow the development of insect resistance. However, the specific mechanisms of compounding need to be studied further so they can be used more effectively in agricultural production and reduce the impact on nontarget organisms.

In addition, these compounding mechanisms may be the reason bumblebees take up mixed insecticides and metabolize them. As the research of Kessler et al. suggests, ${ }^{57}$ honeybees prefer to consume sugar water containing neonicotinoid insecticides, and this preference has led to excessive intake of mixed insecticides. The absorption of one chemical insecticide will change the organism's subsequent rate of insecticide absorption or its metabolism of other drugs, which will affect the impact of another insecticide on bumblebees. Future research is needed on the mixed effects of multiple insecticides on native pollinators such as bumblebees.

\section{Declarations}

\section{Acknowledgements}

We thank Yuhao Wang and Fei Ma for their help in the experiments, and Susan Krusemark for editing and proofreading.

\section{Author Contributions}

Study design and interpretation by Shudong Luo and Hongmei Li-Byarlay. Experiments, statistical analysis, by Yongkui Zhang, Dongqiang Zeng, Lu Li, and Xiuchun Hong. Manuscript preparation by all.

\section{Funding}

This work was supported by the Central Public-interest Scientific Institution Basal Research Fund (Y2018PT66 and Y2021XK16). H. L.-B. was supported by USDA NIFA Evans Allen Fund NI201445XXXXG018 and USDA CBG fund 202138821-34576.

\section{Competing Interests}

The authors declare that they have no known competing financial interests or personal relationships that could have influence the work reported in this paper.

\section{References}

1. Potts, S. G. et al. Global pollinator declines: Trends, impacts and drivers. Trends Ecol. Evol, 25, 345-353 https://doi.org/10.1016/j.tree.2010.01.007 (2010).

2. Goulson, D., Nicholls, E., Botías, C. \& Rotheray, E. L. Bee declines driven by combined stress from parasites, pesticides,and lack of flowers., 347, 1435-1435 https://doi.org/10.1021/acs.est.6b04791 (2015).

3. Simone-Finstrom, M. et al. Migratory management and environmental conditions affect lifespan and oxidative stress in honey bees. Sci. Rep, 6, 32023 https://doi.org/10.1038/srep32023 (2016).

4. Williams, N. M., Regetz, J. \& Kremen, C. Landscape-scale resources promote colony growth but not reproductive performance of bumble bees., 93, 1049-1058 https://doi.org/10.1890/11-1006.1 (2012).

5. Gallai, N., Salles, J. M., Settele, J. \& Vaissière, B. E. Economic valuation of the vulnerability of world agriculture confronted with pollinator decline. Ecol. Econ, 68, 810-821 https://doi.org/10.1016/j.ecolecon.2008.06.014 (2009).

6. Calderone., N. W. Insect pollinated crops, insect pollinators and US agriculture: Trend analysis of aggregate data for the period 1992-2009. PLOS ONE, 7, e37235 https://doi.org/10.1371/journal.pone.0037235 (2012).

7. Hegland, S. J. \& Totland, Ã. Is the magnitude of pollen limitation in a plant community affected by pollinator visitation and plant species specialisation levels?, 117, 883-891 https://doi.org/10.1111/j.2008.0030-1299.16561.x (2008). 
8. Pritchard, D. J. \& Vallejo-Marín, M. Buzz pollination. Curr. Biol, 30, R858-R860 https://doi.org/10.1016/j.cub.2020.05.087 (2020).

9. Vallejo-Marín, M. Buzz pollination: Studying bee vibrations on flowers. New Phytol, 224, 1068-1074 https://doi.org/10.1111/nph.15666 (2019).

10. Switzer, C. M., Russell, A. L., Papaj, D. R., Combes, S. A. \& Hopkins, R. Sonicating bees demonstrate flexible pollen extraction without instrumental learning. Curr. Zool, 65, 425-436 https://doi.org/10.1093/cz/zoz013 (2019).

11. Velthuis, H. H. W. \& van Doorn, A. A century of advances in bumblebee domestication and the economic and environmental aspects of its commercialization for pollination., 37, 421-451 https://doi.org/10.1051/apido:2006019 (2006).

12. Cutler, G. C., Purdy, J., Giesy, J. P. \& Solomon, K. R. Risk to pollinators from the use of chlorpyrifos in the United States. Rev. Environ. Contamin. Toxicol, 231, 219-265 https://doi.org/10.1007/978-3-319-03865-0_7 (2014).

13. Cameron, S. A. et al. Patterns of widespread decline in North American bumble bees. Proc. Natl. Acad. Sci. USA 108, 662-667. https://doi.org/10.1073/pnas.1014743108 (2011)

14. Baron, G. L., Jansen, V. A. A., Brown, M. J. F. \& Raine, N. E. Pesticide reduces bumblebee colony initiation and increases probability of population extinction. Nat. Ecol. Evol, 1, 1308-1316 https://doi.org/10.1038/s41559-017-0260-1 (2017).

15. Meeus, I., Smagghe, G., Siede, R., Jans, K. \& de Graaf, D. C. Multiplex RT-PCR with broad-range primers and an exogenous internal amplification control for the detection of honeybee viruses in bumblebees. J. Invertebr. Pathol, 105, 200-203 https://doi.org/10.1016/j.jip.2010.06.012 (2010).

16. Fürst, M. A., McMahon, D. P., Osborne, J. L., Paxton, R. J. \& Brown, M. J. F. Disease associations between honeybees and bumblebees as a threat to wild pollinators., 506, 364-366 https://doi.org/10.1038/nature12977 (2014).

17. Budge, G. E. et al. Pathogens as predictors of honey bee colony strength in England and Wales. PLoS One, 10, e0133228 https://doi.org/10.1371/journal.pone.0133228 (2015).

18. Nemésio, A., Silva, D. P., Nabout, J. C. \& Varela, S. Effects of climate change and habitat loss on a forest-dependent bee species in a tropical fragmented landscape. Insect Conserv. Divers, 9, 149-160 https://doi.org/10.1111/icad.12154 (2016).

19. Wright, G. A., Nicolson, S. W. \& Shafir, S. Nutritional physiology and ecology of honey bees. Annu. Rev. Entomol, 63, 327344 https://doi.org/10.1146/annurev-ento-020117-043423 (2018).

20. Faleiro, F. V., Nemésio, A. \& Loyola, R. Climate change likely to reduce orchid bee abundance even in climatic suitable sites. Glob. Chang. Biol, 24, 2272-2283 https://doi.org/10.1111/gcb.14112 (2018).

21. Gill, R. J. \& Raine, N. E. Chronic impairment of bumblebee natural foraging behaviour induced by sublethal pesticide exposure. Funct. Ecol, 28, 1459-1471 https://doi.org/10.1111/1365-2435.12292 (2014).

22. Gill, R. J., Ramos-Rodriguez, O. \& Raine, N. E. Combined pesticide exposure severely affects individual-and colony-level traits in bees., 491, 105-108 https://doi.org/10.1038/nature11585 (2012).

23. Laycock, I., Lenthall, K. M., Barratt, A. T. \& Cresswell, J. E. Effects of imidacloprid, a neonicotinoid pesticide, on reproduction in worker bumble bees (Bombus terrestris). Ecotoxicology 21, 1937-1945.

https://doi.org/10.1007/s10646-012-0927-y (2012)

24. Laycock, l., Cotterell, K. C., O'Shea-Wheller, T. A. \& Cresswell, J. E. Effects of the neonicotinoid pesticide thiamethoxam at field-realistic levels on microcolonies of Bombus terrestris worker bumble bees. Ecotoxicol. Environ. Saf, 100, 153-158 https://doi.org/10.1016/j.ecoenv.2013.10.027 (2014).

25. Ellis, C., Park, K. J., Whitehorn, P., David, A. \& Goulson, D. The neonicotinoid insecticide thiacloprid impacts upon bumblebee colony development under field conditions. Environ. Sci. Technol, 51, 1727-1732 https://doi.org/10.1021/acs.est.6b04791 (2017).

26. Mullin, C. A. et al. High levels of miticides and agrochemicals in North American apiaries: Implications for honey bee health. PLoS One, 5, e9754 https://doi.org/10.1371/journal.pone.0009754 (2010). 
27. Daniele, G., Giroud, B., Jabot, C. \& Vulliet, E. Exposure assessment of honeybees through study of hive matrices: Analysis of selected pesticide residues in honeybees, beebread, and beeswax from French beehives by LC-MS/MS. Environ. Sci. Pollut. Res. Int, 25, 6145-6153 https://doi.org/10.1007/s11356-017-9227-7 (2017).

28. Giroud, B., Vauchez, A., Vulliet, E., Wiest, L. \& Bulete, A. Trace level determination of pyrethroid and neonicotinoid insecticides in beebread using acetonitrile-based extraction followed by analysis with ultra-high-performance liquid chromatography-tandem mass spectrometry. J. Chromatogr. A, 1316, 53-61 https://doi.org/10.1016/j.chroma.2013.09.088 (2013).

29. Sanchez-Bayo, F. \& Goka, K. Pesticide residues and bees-A risk assessment. PLoS One, 9, e94482 https://doi.org/10.1371/journal.pone.0094482 (2014).

30. Vázquez, P. P., Lozano, A., Uclés, S., Gómez Ramos, M. M. \& Fernández-Alba, A. R. A sensitive and efficient method for routine pesticide multiresidue analysis in bee pollen samples using gas and liquid chromatography coupled to tandem mass spectrometry. J. Chromatogr. A, 1426, 161-173 https://doi.org/10.1016/j.chroma.2015.11.081 (2015).

31. Kasiotis, K. M., Anagnostopoulos, C., Anastasiadou, P. \& Machera, K. Pesticide residues in honeybees, honey and bee pollen by LC-MS/MS screening: Reported death incidents in honeybees. Sci. Total Environ, 485-486, 633-642 https://doi.org/10.1016/j.scitotenv.2014.03.042 (2014).

32. Pettis, J. S. et al. Crop pollination exposes honey bees to pesticides which alters their susceptibility to the gut pathogen Nosema ceranae. PLoS One, 8, e70182 https://doi.org/10.1371/journal.pone.0070182 (2013).

33. Tong, Z. et al. A survey of multiple pesticide residues in pollen and beebread collected in China. Sci. Total Environ, 640641, 1578-1586 https://doi.org/10.1016/j.scitotenv.2018.04.424 (2018).

34. Wen, X. et al. Pesticide residues in the pollen and nectar of oilseed rape (Brassica napus L.) and their potential risks to honey bees. Science of the Total Environment, 786, 147443 https://doi.org/10.1016/j.scitotenv.2021.147443 (2021).

35. Yue, M., Luo, S., Liu, J. \& Wu, J.J. Econ. Entomol.111,39-42. https://doi.org/10.1093/jee/tox342 (2017)

36. Organization for Economic Co-operation and Development (OECD). Test No. 247: Bumblebee, Acute Oral Toxicity Test. (OECD, 2017)

37. Liu et al. Application of the combination index (Cl)-isobologram equation to research the toxicological interactions of clothianidin, thiamethoxam, and dinotefuran in honeybee, Apis mellifera., 184, 806-811

https://doi.org/10.1016/j.chemosphere.2017.06.045 (2017).

38. Finney, D. J. Probit Analysis 3rd edn (Cambridge University Press, 1971). https://doi.org/10.2307/2986688

39. Chou, T. C. \& Talalay, P. Quantitative analysis of dose-effect relationships: The combined effects of multiple drugs or enzyme inhibitors. Adv. Enzyme Regul, 22, 27-55 https://doi.org/10.1016/0065-2571(84)90007-4 (1984).

40. Chou, T. \& Martin, N. CompuSyn for Drug Combinations. PC Software and User's Guide: A Computer Program for Quantitation of Synergism and Antagonism in Drug Combinations and the Determination of IC50 and ED50 and LD50 Values (ComboSyn Inc., 2005).

41. Chou, T. C. Theoretical basis, experimental design, and computerized simulation of synergism and antagonism in drug combination studies. Pharmacol. Rev, 58, 621-681 https://doi.org/10.1124/pr.58.3.10 (2006).

42. Jeschke, P. \& Nauen, R. Neonicotinoids-From zero to hero in insecticide chemistry. Pest Manag. Sci, 64, 1084-1098 https://doi.org/10.1002/ps.1631 (2008).

43. Bonmatin, J. M. et al. Environmental fate and exposure; neonicotinoids and fipronil. Environ. Sci. Pollut. Res, 22, 35-67 https://doi.org/10.1007/s11356-014-3332-7 (2015).

44. Dussaubat, C. et al. Combined neonicotinoid pesticide and parasite stress alter honeybee queens' physiology and survival. Sci. Rep, 6, $31430 \mathrm{https://doi.org/10.1038/srep31430} \mathrm{(2016).}$

45. Ma, C. et al. Impact of acute oral exposure to thiamethoxam on the homing, flight, learning acquisition and short-term retention of Apis cerana. Pest Manag. Sci, 75, 2975-2980 https://doi.org/10.1002/ps.5411 (2019). 
46. Chen, C., Wang, Y., Zhao, X., Qian, Y. \& Wang, Q. Combined toxicity of butachlor, atrazine and $\lambda$-cyhalothrin on the earthworm Eisenia fetida by combination index (Cl)-isobologram method., 112, 393-401

https://doi.org/10.1016/j.chemosphere.2014.04.070 (2014).

47. Rodea-Palomares, I. et al. Application of the combination index $(\mathrm{Cl})$-isobologram equation to study the toxicological interactions of lipid regulators in two aquatic bioluminescent organisms. Water Res, 44, 427-438

https://doi.org/10.1016/j.watres.2009.07.026 (2010).

48. González-Pleiter, M. et al. Toxicity of five antibiotics and their mixtures towards photosynthetic aquatic organisms: Implications for environmental risk assessment. Water Res, 47, 2050-2064

https://doi.org/10.1016/j.watres.2013.01.020 (2013).

49. Wang, Y., Chen, C., Qian, Y., Zhao, X. \& Kong, X. Toxicity of mixtures of $\lambda$-cyhalothrin, imidacloprid and cadmium on the earthworm Eisenia fetida by combination index (Cl)-isobologram method. Ecotoxicol. Environ. Saf, 111, 242-247 https://doi.org/10.1016/j.ecoenv.2014.10.015 (2015).

50. Matsuda, K. et al. Insecticides acting on insect nicotinic acetylcholine receptors. Trends Pharmacol. Sci, 22, 573-580 https://doi.org/10.1016/S0165-6147(00)01820-4 (2001).

51. Elbert, A., Haas, M., Springer, B., Thielert, W. \& Nauen, R. Applied aspects of neonicotinoid uses in crop protection. Pest Manag. Sci, 64, 1099-1105 https://doi.org/10.1002/ps.1616 (2008).

52. Tomizawa, M., Kagabu, S. \& Casida, J. E. Receptor structure-guided neonicotinoid design. J. Agric. Food Chem, 59, 2918-2922 https://doi.org/10.1021/jf102523s (2011).

53. Soto-Mancera, F., Arellano, J. M. \& Albendín, M. G. Carboxylesterase in Sparus aurata: Characterisation and sensitivity to organophosphorus pesticides and pharmaceutical products. Ecol. Indic, 109, 105603 https://doi.org/10.1016/j.ecolind.2019.105603 (2019).

54. Nauen, R., Ebbinghaus-Kintscher, U., Salgado, V. L. \& Kaussmann, M. Thiamethoxam is a neonicotinoid precursor converted to clothianidin in insects and plants. Pestic. Biochem. Physiol, 76, 55-69 https://doi.org/10.1016/S00483575(03)00065-8 (2003).

55. Wiesner, P. \& Kayser, H. Characterization of nicotinic acetylcholine receptors from the insects Aphis craccivora, Myzus persicae, and Locusta migratoria by radioligand binding assays: Relation to thiamethoxam action. J. Biochem. Mol. Toxicol, 14, 221-230 https://doi.org/10.1002/(SICI)1099-0461(2000)14:4<221:AID-JBT7>3.0.C0;2-6 (2015).

56. Food and Agriculture Organization of the United Nations (FAO). Imidacaloprid (FAO, 2013).

57. Food and Agriculture Organization of the United Nations (FAO). Thiamethoxam (FAO, 2010).

58. Kessler, S. C. et al. Bees prefer foods containing neonicotinoid pesticides., 521, 74-76 https://doi.org/10.1038/nature14414 (2015).

\section{Tables}

Table 1. Acute oral toxicity of pesticides ( $\mathrm{LD}_{50}$ value) to bumblebees. Different lowercase letters in the same subcolumn indicate a significant difference among the bumblebees to different pesticide(s) (one-way ANOVA followed by Duncan's tests). $\mathrm{Cl}=$ combination index; $\mathrm{C}=$ chlorpyrifos; $\mathrm{I}=$ imidacloprid; $\mathrm{T}$ = thiamethoxam. 


\begin{tabular}{llll} 
Pesticide(s) & Mean \pm SE ( $\mu$ g/bee) & $95 \% \mathrm{Cl}$ & \\
\hline $\mathrm{C}$ & $0.568 \pm 0.123 \mathrm{c}$ & 0.041 & 1.095 \\
\hline $\mathrm{I}$ & $0.310 \pm 0.061 \mathrm{ab}$ & 0.049 & 0.571 \\
\hline $\mathrm{T}$ & $0.438 \pm 0.030 \mathrm{bc}$ & 0.31 & 0.566 \\
\hline $\mathrm{C}+\mathrm{I}$ & $0.860 \pm 0.012 \mathrm{~d}$ & 0.807 & 0.912 \\
\hline $\mathrm{C}+\mathrm{T}$ & $0.224 \pm 0.008 \mathrm{a}$ & 0.19 & 0.257 \\
\hline $\mathrm{I}+\mathrm{T}$ & $0.205 \pm 0.028 \mathrm{a}$ & 0.083 & 0.327 \\
\hline $\mathrm{C}+\mathrm{I}+\mathrm{T}$ & $0.293 \pm 0.041 \mathrm{ab}$ & 0.118 & 0.468
\end{tabular}

Table 2. Dose-effect relationship parameters and mean combination index (Cl) values of chlorpyrifos (C), imidacloprid (I), and thiamethoxam $(\mathrm{T})$ singly and in binary and ternary combinations in bumblebee tests after $48 \mathrm{~h}$ of exposure. The computer software CompuSyn was used to calculating the $D_{m}, m, r$, and $\mathrm{Cl}$ values. The parameters $D_{m}, m$, and $r$ are the antilog of the $x$-intercept, the slope, and the linear correlation coefficient of the median-effect plot, which indicate the potency $\left(\mathrm{LD}_{50}\right)$, the shape of the dose-effect curve, and the conformity of the data to the mass-action law, respectively ${ }^{38,39,40}$. The $D_{m}$ and $m$ values were used to calculate the $\mathrm{Cl}$ values (equation (4)), and $\mathrm{Cl}<1, \mathrm{Cl}>1$, and $\mathrm{Cl}=1$ represent synergism, antagonism, and an additive effect, respectively. $L D_{10}, L_{5}$, and $L D_{90}$ are the doses producing a $10 \%, 50 \%$, and $90 \%$ mortality rate in bumblebees, respectively. Doses are in micrograms of active ingredient per bee.

\begin{tabular}{|c|c|c|c|c|c|}
\hline \multirow[t]{2}{*}{ Pesticide(s) } & \multicolumn{2}{|c|}{ Dose-effect parameter } & \multicolumn{3}{|c|}{$\mathrm{Cl}$ value at } \\
\hline & $D_{m}$ & $m$ & $\mathrm{LD}_{10}$ & $\mathrm{LD}_{50}$ & $\mathrm{LD}_{90}$ \\
\hline C & 0.76593 & 2.31045 & - & - & - \\
\hline I & 0.23393 & 0.846 & - & - & - \\
\hline $\mathrm{T}$ & 0.43628 & 5.9474 & - & - & - \\
\hline$C+1$ & 0.88767 & 4.15344 & 8.2139 & 1.76069 & 0.69604 \\
\hline$C+T$ & 0.22549 & 9.38724 & 0.599 & 0.37311 & 0.25261 \\
\hline$I+T$ & 0.19715 & 2.2892 & 1.68173 & 0.589 & 0.58701 \\
\hline$C+I+T$ & 0.31454 & 2.1166 & 1.33942 & 0.65273 & 0.70644 \\
\hline
\end{tabular}

Figures 


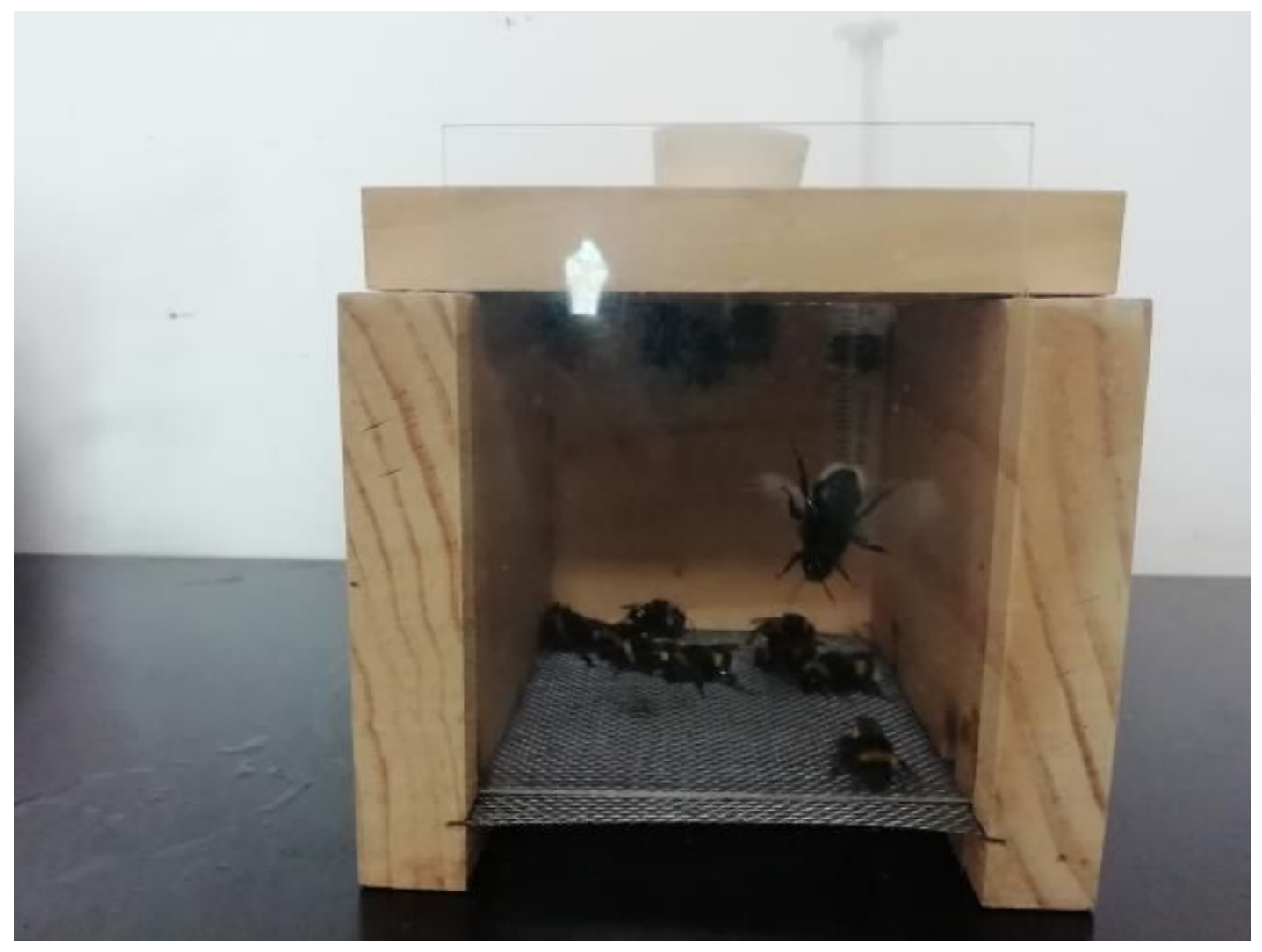

\section{Figure 1}

Bumblebees in the wooden test box.

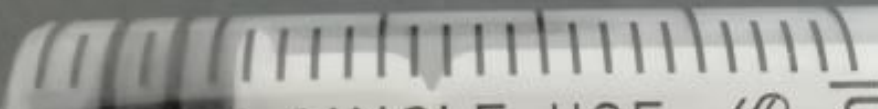 SINGLE USE}




\section{Figure 2}

A $5 \mathrm{~mL}$ syringe with the tip removed.
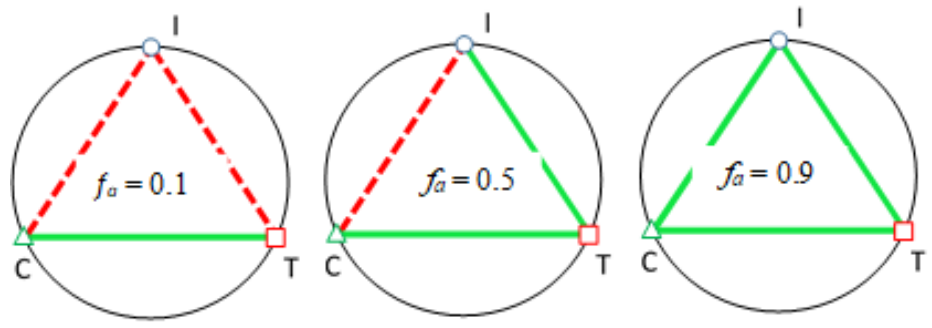

Figure 3

Polygonograms showing the toxicological interactions of imidacloprid (I), chlorpyrifos (C), and thiamethoxam (T) in total combinations when calculated by CompuSyn for the mortality rate of honeybees at three representative effect levels (fa), $0.1,0.5$, and 0.9 , after an exposure for $48 \mathrm{~h}$. Solid lines represent synergism, and the strength of each synergism is indicated by the thickness of the line.
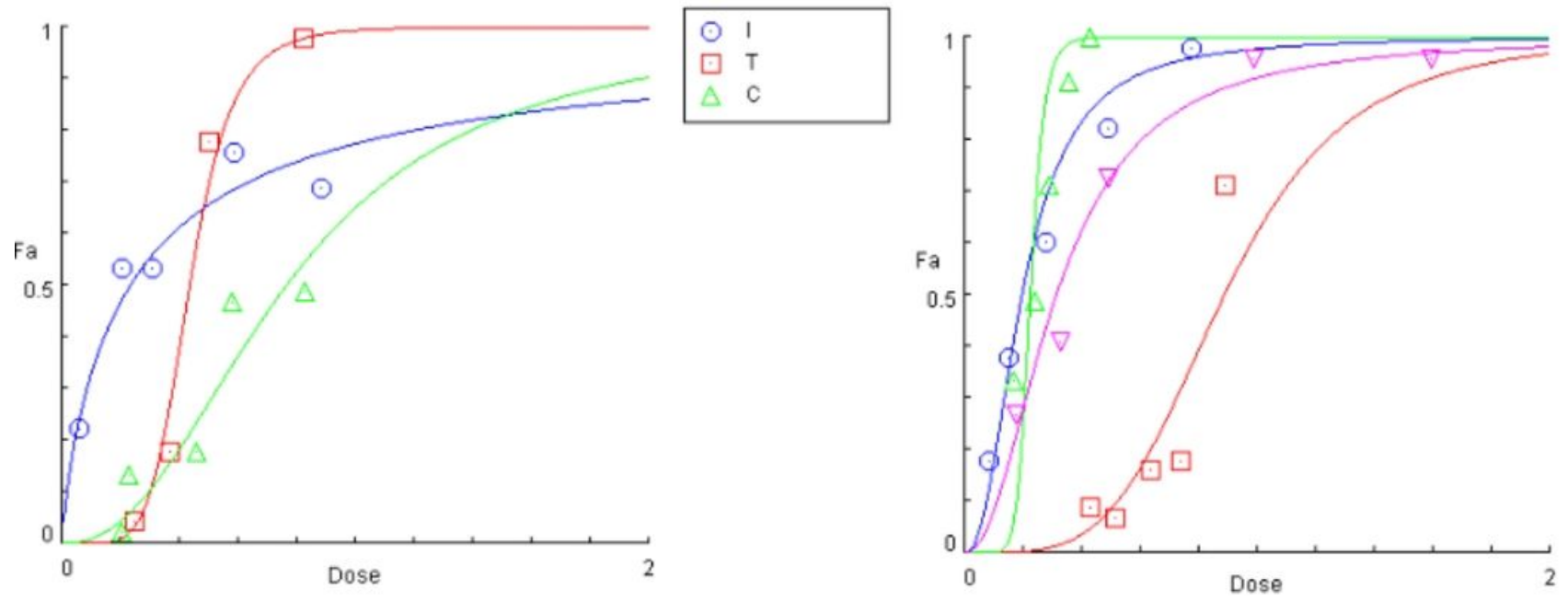

\section{Figure 4}

Dose-effect diagram of drugs (left) and drug combinations (right). 